\title{
Determination of nitric oxide metabolites, nitrate and nitrite, in Anopheles culicifacies mosquito midgut and haemolymph by anion exchange high-performance liquid chromatography: plausible mechanism of refractoriness
}

\author{
Arun Sharma*1, Kamaraju Raghavendra ${ }^{2}$, Tridibesh Adak ${ }^{3}$ and \\ Aditya P Dash ${ }^{4}$
}

Address: ${ }^{1}$ Protein Biochemistry Laboratory, National Institute of Malaria Research (ICMR), 22 Sham Nath Marg, Delhi- 110 054, India, ${ }^{2}$ Molecular Entomology Laboratory, National Institute of Malaria Research (ICMR) 22 Sham Nath Marg, Delhi- 110 054, India, ${ }^{3}$ Entomology Laboratory, National Institute of Malaria Research (ICMR) 2, Nanak Enclave, Delhi-110 009, India and ${ }^{4}$ National Institute of Malaria Research (ICMR), 22 Sham Nath Marg, Delhi- 110 054, India

Email: Arun Sharma* - sharmaaru20032003@yahoo.co.in; Kamaraju Raghavendra - kamarajur2000@yahoo.com; Tridibesh Adak - adak@mrcindia.org; Aditya P Dash - dashap@icmr.org.in

* Corresponding author

Published: 28 April 2008

Malaria Journal 2008, 7:71 doi:I0.1 I86/I475-2875-7-7I
Received: 3I December 2007

Accepted: 28 April 2008

This article is available from: http://www.malariajournal.com/content/7/I/7I

(C) 2008 Sharma et al; licensee BioMed Central Ltd.

This is an Open Access article distributed under the terms of the Creative Commons Attribution License (http://creativecommons.org/licenses/by/2.0), which permits unrestricted use, distribution, and reproduction in any medium, provided the original work is properly cited.

\begin{abstract}
Background: The diverse physiological and pathological role of nitric oxide in innate immune defenses against many intra and extracellular pathogens, have led to the development of various methods for determining nitric oxide (NO) synthesis. NO metabolites, nitrite $\left(\mathrm{NO}_{2}{ }^{-}\right)$and nitrate $\left(\mathrm{NO}_{3}{ }^{-}\right)$are produced by the action of an inducible Anopheles culicifacies NO synthase (AcNOS) in mosquito mid-guts and may be central to anti-parasitic arsenal of these mosquitoes.

Method: While exploring a plausible mechanism of refractoriness based on nitric oxide synthase physiology among the sibling species of An. culicifacies, a sensitive, specific and cost effective high performance liquid chromatography (HPLC) method was developed, which is not influenced by the presence of biogenic amines, for the determination of $\mathrm{NO}_{2}{ }^{-}$and $\mathrm{NO}_{3}{ }^{-}$from mosquito mid-guts and haemolymph.

Results: This method is based on extraction, efficiency, assay reproducibility and contaminant minimization. It entails de-proteinization by centrifugal ultra filtration through ultracel $3 \mathrm{~K}$ filter and analysis by high performance anion exchange liquid chromatography (Sphereclone, $5 \mu$ SAX column) with UV detection at $214 \mathrm{~nm}$. The lower detection limit of the assay procedure is 50 pmoles in all midgut and haemolymph samples. Retention times for $\mathrm{NO}_{2}{ }^{-}$and $\mathrm{NO}_{3}{ }^{-}$in standards and in mid-gut samples were 3.42 and 4.53 min. respectively. Assay linearity for standards ranged between $50 \mathrm{nM}$ and I mM. Recoveries of $\mathrm{NO}_{2}{ }^{-}$and $\mathrm{NO}_{3}{ }^{-}$from spiked samples $(\mathrm{I}-\mathrm{I} 00 \mu \mathrm{M})$ and from the extracted standards $(1-100 \mu M)$ were calculated to be $100 \%$. Intra-assay and inter assay variations and relative standard deviations (RSDs) for $\mathrm{NO}_{2}{ }^{-}$and $\mathrm{NO}_{3}{ }^{-}$in spiked and un-spiked midgut samples were $5.7 \%$ or less. Increased levels $\mathrm{NO}_{2}{ }^{-}$and $\mathrm{NO}_{3}{ }^{-}$in midguts and haemolymph of An. culicifacies sibling species $\mathrm{B}$ in comparison to species $\mathrm{A}$ reflect towards a mechanism of refractoriness based on AcNOS physiology.
\end{abstract}

Conclusion: HPLC is a sensitive and accurate technique for identification and quantifying pmole levels of NO metabolites in mosquito midguts and haemolymph samples that can be useful for clinical investigations of NO biochemistry, physiology and pharmacology in various biological samples. 


\section{Background}

Potential control efforts for malaria mainly include vaccine development, vector control and development of new anti-malarial drugs [1]. Vector control has become increasingly difficult due to mosquito resistance to insecticides [2] and efforts to replace natural vectors with mosquitoes that do not support parasite development are under study and may contribute to malaria control in long term $[3,4]$. Advances in the molecular genetic manipulations of insect species have led to speculation that malaria could be controlled through genetic alterations of Anopheline mosquitoes rendered refractory to Plasmodium growth and differentiation $[5,6]$. While assessing natural susceptibility of Anopheles culicifacies sensu lato from different geographical areas against Plasmodium vivax infection, an isofemale line was found, which was found to be $100 \%$ refractory to Plasmodium vivax infection. This iso-female line was later identified as An. culicifacies species B [7].

The mosquito midgut is the first major site of interaction between the parasite and the mosquito. Failure of the parasite to negotiate this environment can be a barrier for development and is likely the main cause of mosquito refractoriness. The sporogonic development of Plasmodium, from gamete to oocyst formation, takes place in the lumen and epithelium of the mosquito midgut $[8,9]$ and some mosquito-specific factors probably determine the outcome of this sporogonic development [10]. It has long been recognized that mosquitoes possess highly effective innate defense mechanisms of both cellular and humoral nature $[11,12]$. Such responses may be important for the vectorial capacity of the mosquito and understanding of parasite-vector interactions and mechanism of refractoriness. It was also shown by Luckart et al [13] that a nitric oxide synthase (NOS) gene in Anopheles stephensi is transcriptionally activated at a modest level after malaria infection to limit the development of parasites $[13,14]$. Induction of AcNOS (An. culicifacies NOS) expression is proportional to the intensity of parasite infection and is detectable in the midgut by $6 \mathrm{~h}$ post infection [15].

NO metabolites, nitrite $\left(\mathrm{NO}_{2}^{-}\right)$and nitrate $\left(\mathrm{NO}_{3}{ }^{-}\right)$are produced by the action of an inducible An. culicifacies $\mathrm{NO}$ synthase (AcNOS) in mosquito midguts and may be central to anti-parasitic arsenal of these mosquitoes $[15,16]$. Measurements of nitrite $\left(\mathrm{NO}_{2}^{-}\right)$and nitrate $\left(\mathrm{NO}_{3}{ }^{-}\right)$in midguts and haemolymph of mosquitoes are proposed indices to reflect accurately cellular nitric oxide production and represents a considerable analytical challenge. The diverse physiological and pathological roles of nitric oxide in innate immune defenses against many intra and extracellular pathogens, have led to the development of various methods for determining nitric oxide (NO) synthesis [16-25]. Because $\mathrm{NO}$ is a free radical molecule released by cells in picomolar to nanomolar ranges and has a very short life, a direct measurement of it is difficult [19]. Measurement of nitrite and nitrate, the stable products of NO oxidation, has often been performed to assess NO synthesis in various biological systems [20,25]. A number of ion exchange and reversed phase ion paired HPLC methods have been developed for measuring nitrite and nitrate in biological systems with detection by either UV-VIS absorbance [21] or fluorescence [22] or chemiluminiscence [23] or conductivity [24]. Most HPLC methods require several purification steps to remove interfering substances such as chloride and biogenic amines and therefore, the results may vary considerably [25-27]. Thus, quantification of pico-mole levels of nitrite and nitrate in biological samples is still a challenge.

The aim of the present study was to determine midgut and haemolymph levels of nitrite and nitrate in An. culicifacies refractory species $B$ and compares it with sensitive species A over the course of time to evaluate the mechanism of refractoriness and the performance of a novel HPLC method. The HPLC method offers high sensitivity and specificity as well as easy automation for the determination of pico-mole levels of nitrite and nitrate in mosquito midguts and haemolymph. This procedure may also be suitable for routine determination of $\mathrm{NO}_{2}{ }^{-}$and $\mathrm{NO}_{3}{ }^{-}$in various other biological fluids/samples.

\section{Methods \\ Materials}

HPLC-grade water was purchased from Thomas Baker (India) and was used for the preparation of the mobile phase solution. Double distilled and deionised (DDwater) was used for preparing other solutions. Potassium dihydrogen phosphate $\left(\mathrm{KH}_{2} \mathrm{PO}_{4}\right)$, Potassium phosphate $\left(\mathrm{K}_{2} \mathrm{HPO}_{4}\right)$, Potassium nitrite $\left(\mathrm{KNO}_{2}\right)$, Potassium nitrate $\left(\mathrm{KNO}_{3}\right)$ was purchased from Sigma (St. Louis, MO, USA). Intermediate and working standard solutions covered the concentration range reported and were prepared by diluting the stock standard solutions with water. All solutions were stored at $4{ }^{\circ} \mathrm{C}$.

\section{Mosquito rearing and blood-feeding}

Indoor-resting wild An. culicifacies s.l. adult females were collected from human dwellings by hand catch method and transported to laboratory. The iso-female progenies obtained from wild female mosquitoes were held separately in $30 \times 30 \times 30 \mathrm{cms}$ cloth cages and kept in the insectary maintained at temperature $27 \pm 2{ }^{\circ} \mathrm{C}$ and $75 \pm$ $5 \%$ relative humidity (RH) with photoperiod of $14 \mathrm{hr}$ light and $10 \mathrm{hr}$ dark. Adult mosquitoes were offered water soaked raisins and $1 \%$ glucose soaked cotton pads as a source of energy. Few adult female mosquitoes from each $\mathrm{F}_{1}$ iso-female progeny were identified to sibling species using species-specific diagnostic inversion genotypes as described by Subbarao et al. [28]. At least 50 to 60 iso- 
female lines from a particular geographical locality showing species-specific diagnostic inversion genotype of species B were pooled together to establish a strain. This isofemale line was later identified as sibling species B and designated as $P$. vivax refractory strain. The susceptibility of all these species B strains was assessed in the laboratory against $P$. vivax, the predominant human malaria parasite species in India.

In each feeding experiment, cohorts of 50 mosquitoes from each of species A and species B strains starved for 12-16 hours were used [29]. About 2-3 ml of $P$. vivax infected blood was drawn from consenting volunteer patient (aged $\geq 16$ yrs) having mature $P$. vivax gametocytes density ranging between 0.05 to $0.5 \%$ following human use protocol approved by the Human Ethical Committee of the Centre as described by earlier [30]. All P.vivax positive patients were treated with $600 \mathrm{mg}$ chloroquine once on day ' 0 ' and $15 \mathrm{mg}$ of primaquine for five consecutive days (adult dose) following national drug policy of National Vector Borne Disease Control Programme (NVBDCP), Government of India.

The mosquitoes were fed on P. vivax-infected blood through a membrane feeding system, essentially following the method as described by Adak et al [30]. In all feeding experiments, laboratory reared An. stephensi, which are highly susceptible to $P$. vivax infection, were also fed parallely along with all species A and species B strains on the same blood sample, to assess the comparative infectiousness to mosquitoes. The controls and infected mosquitoes were fed at the same time to minimize the variations in mosquitoes colonies sampled at different times.

After 30 minutes of feeding, unfed and partially fed mosquitoes from each cohort were removed, only fully engorged mosquitoes were kept securely in $30 \times 30 \times 30$ $\mathrm{cms}$ cloth cages in the insectary for subsequent examination of sporogonic development. Minimum of $50 \%$ of the surviving An. culicifacies and An. stephensi mosquitoes from each feeding experiment, fed on the same blood isolate were dissected on day ' 7 ' and ' $9-10$ ' and ' $14-15$ ' in PBSI (phosphate-buffered saline containing $1 \mathrm{mM}$ EDTA and $1 \mathrm{mg} / \mathrm{ml}$ Pefabloc ${ }^{\circledR}$ ). Subsequently, midguts and haemolymph were collected for further analysis.

\section{Midgut and haemolymph preparation}

All dissections were performed on ice, in PBSI. Midguts and haemolymph samples were simultaneously isolated from individually dissected mosquitoes and were pooled (50 samples) from sugar fed (0 day) and uninfected and infected blood fed mosquitoes (7, 9-10, and 14 days). The controls and infected mosquitoes were fed at the same time to minimize the variations in mosquitoes colonies sampled at different times.
Midguts were dissected from sugar-fed female (0-day) mosquitoes. Midguts from blood-fed mosquitoes were opened by a longitudinal incision and haemolymph was directly collected and pooled. Midguts were thoroughly rinsed three times in ice-cold PBSI to remove all traces of peritrophic matrix and gut contents. Haemolymph and dissected mid-guts were stored at $-80^{\circ} \mathrm{C}$ until processing.

\section{Samples extraction}

Mosquito midguts and haemolymph were sonicated and diluted with equal volume of HEPES buffer $(10 \mathrm{mM}$ HEPES, $140 \mathrm{mM} \mathrm{NaCl}, 2.7 \mathrm{mM} \mathrm{KCl}, 1 \mathrm{mM} \mathrm{CaCl}, 1 \mathrm{mM}$ $\mathrm{MgCl}_{2}, 5 \mathrm{mM}$ glucose, $1 \mathrm{mg} / \mathrm{ml}$ bovine serum albumin, $\mathrm{pH} 7.4$ ) and centrifuged at $1,500 \mathrm{~g}$. Supernatants were obtained from washed midgut and haemolymph samples in HEPES buffer for analysis of $\mathrm{NO}_{2}{ }^{-}$and $\mathrm{NO}_{3}{ }^{-}$and normalized for their protein content between individual groups. Prior to analysis, samples $(200 \mu \mathrm{l})$ were centrifuged for $30 \mathrm{~min}$ through a Microsep (3.5 ml capacity) 3 $\mathrm{K}$ micro concentrator filters (Ultracel YM-3, Millipore Co.) at $11,000 \mathrm{~g}$ and $3,000 \mathrm{~g}$ respectively to remove all the proteins. Filters had been pre-washed with deionized water with centrifugation and disposal of the wastes.

Aliquots of each individually filtered sample extracts were spiked with $25 \mu \mathrm{M}$ aqueous $\mathrm{KNO}_{2}-/ \mathrm{KNO}_{3}$ - standards as at this concentration the recovery is $100 \%$ (Table 1). $20 \mu \mathrm{l}$ of spiked sample extracts were directly injected onto the chromatograph. Sample concentrations were corrected for silica column $\mathrm{NO}_{2}-\mathrm{NO}_{3}$ - contamination by subtracting the values obtained with water which has also been subjected to extraction procedure.

\section{Instrument}

The chromatograph comprised a Shimadzu Sil-10AD sample injector port with a $100 \mu \mathrm{l}$ sample loop, a Shi-

Table I: Recoveries of $\mathrm{NO}_{2}^{-}$and $\mathrm{NO}_{3}{ }^{-}$in extracted $\mathrm{KNO}_{2} / \mathrm{KNO}_{3}$ standards (Mean \pm SD, $n=8$ )

\begin{tabular}{ccc}
\hline Concentration & \multicolumn{2}{c}{ Recovery (\%) } \\
\cline { 2 - 3 } & $\mathrm{NO}_{2}^{-}$ & $\mathrm{NO}_{3}^{-}$ \\
\hline $48 \mathrm{nM}$ & $90.7 \pm 1.9$ & $28.3 \pm 3.4$ \\
$97 \mathrm{nM}$ & $94.5 \pm 6.2$ & $54.8 \pm 4.3$ \\
$195 \mathrm{nM}$ & $94.7 \pm 5.9$ & $87.8 \pm 5.1$ \\
$390 \mathrm{nM}$ & $93.4 \pm 4.0$ & $80.2 \pm 1.5$ \\
$780 \mathrm{nM}$ & $93.6 \pm 1.9$ & $93.7 \pm 4.5$ \\
$1.56 \mu \mathrm{M}$ & $93.7 \pm 2.9$ & $87.9 \pm 3.9$ \\
$3.12 \mu \mathrm{M}$ & $91.8 \pm 1.6$ & $95.2 \pm 2.9$ \\
$6.25 \mu \mathrm{M}$ & $98.5 \pm 2.4$ & $98.5 \pm 3.1$ \\
$12.5 \mu \mathrm{M}$ & $97.1 \pm 1.8$ & $94.8 \pm 1.9$ \\
$25 \mu \mathrm{M}$ & $99 \pm 5.4$ & $100.5 \pm 3.2$ \\
$50 \mu \mathrm{M}$ & $100 \pm 5.8$ & $97.3 \pm 2.9$ \\
$100 \mu \mathrm{M}$ & $97.1 \pm 2.4$ & $99.2 \pm 4.9$
\end{tabular}


madzu LC-10AT liquid chromatography pump, a UV-VIS detector SPD10 AV and a Shimadzu LC-workstation (all instruments Shimadzu, Tokyo, Japan). The column (250 $\times 4.6 \mathrm{~mm}$, Sphereclone $5 \mu$ SAX, Phenomenex Co. USA), was an anion exchanger (SEM based on silica). The mobile phase was pumped at a rate of $1.5 \mathrm{ml} / \mathrm{min}$ and consisted of $5 \mathrm{mM} \mathrm{K}_{2} \mathrm{HPO}_{4}$ and $25 \mathrm{MM} \mathrm{KH}_{2} \mathrm{PO}_{4}$, pH 3.0. The effluent was monitored at $214 \mathrm{~nm}$. The injection volume was $20 \mu \mathrm{l}$ and the column and samples were kept at $35 \pm 5^{\circ} \mathrm{C}$ and $4 \pm 5^{\circ} \mathrm{C}$, respectively.

\section{Calculation of sample $\mathrm{NO}_{2}{ }_{-}^{-}$and $\mathrm{NO}_{3}{ }^{-}$concentrations}

Sample $\mathrm{NO}_{2}$ - and $\mathrm{NO}_{3}{ }^{-}$concentrations were calculated by reference to $\mathrm{KNO}_{2}{ }^{-} / \mathrm{KNO}_{3}{ }^{-}$standard mixtures. Chromatogram peak areas in preference to peak heights were used in these calculations as these were found to yield more reproducible results. These were measured manually with peak "skimming" being employed where necessary. Where appropriate sample concentrations were corrected for background contamination with $\mathrm{NO}_{2}{ }^{-}$and $\mathrm{NO}_{3}{ }^{-}$in water and buffer solutions.

\section{Assay validation}

Several criteria associated with the assay validation were undertaken according to ICH guidelines [31] so as to define the method's selectivity, linearity, and lower limit of detection, lower limit of quantitation, precision, accuracy and recovery from biological samples.

\section{Statistical analysis}

Data are expressed as mean and standard error of the mean $(\mathrm{n}=3)$ and analysed using 2-way ANOVA (Friedman test). Probability values of $p<0.05$ were considered statistically significant.

\section{Results}

Typical chromatographic traces of nitrite and nitrate obtained after extraction and direct injection from the standard, mosquito gut samples and mosquito haemolymph samples are presented in Figure 1. The limit of quantification in midguts and haemolymph samples was defined as the lowest concentration of nitrite and nitrate resulting in a signal-to-noise ratio of 3:1. The lowest detection limit was $0.1 \mu$ mole/l. The retention times for $\mathrm{NO}_{2}{ }^{-}$ and $\mathrm{NO}_{3}$ - in standard solutions were (mean $\left.\pm \mathrm{SD}\right) 3.400$ and 4.533 min. respectively $(n=8)$.

In mosquito midgut the retention times $(\mathrm{n}=8)$ were 3.400 and $4.525 \mathrm{~min}$. respectively and haemolymph samples the retention times were found to be 3.433 and 4.525 min (Fig. 1). Chromatogram peak identities for samples extracts were confirmed in spiking experiments in which known quantities of $\mathrm{NO}_{2}^{-}$and $\mathrm{NO}_{3}^{-}$standards were added.

\section{Recovery}

Recovery is expressed as the amount of analyte found as a percentage to the theoretical amount thought to be
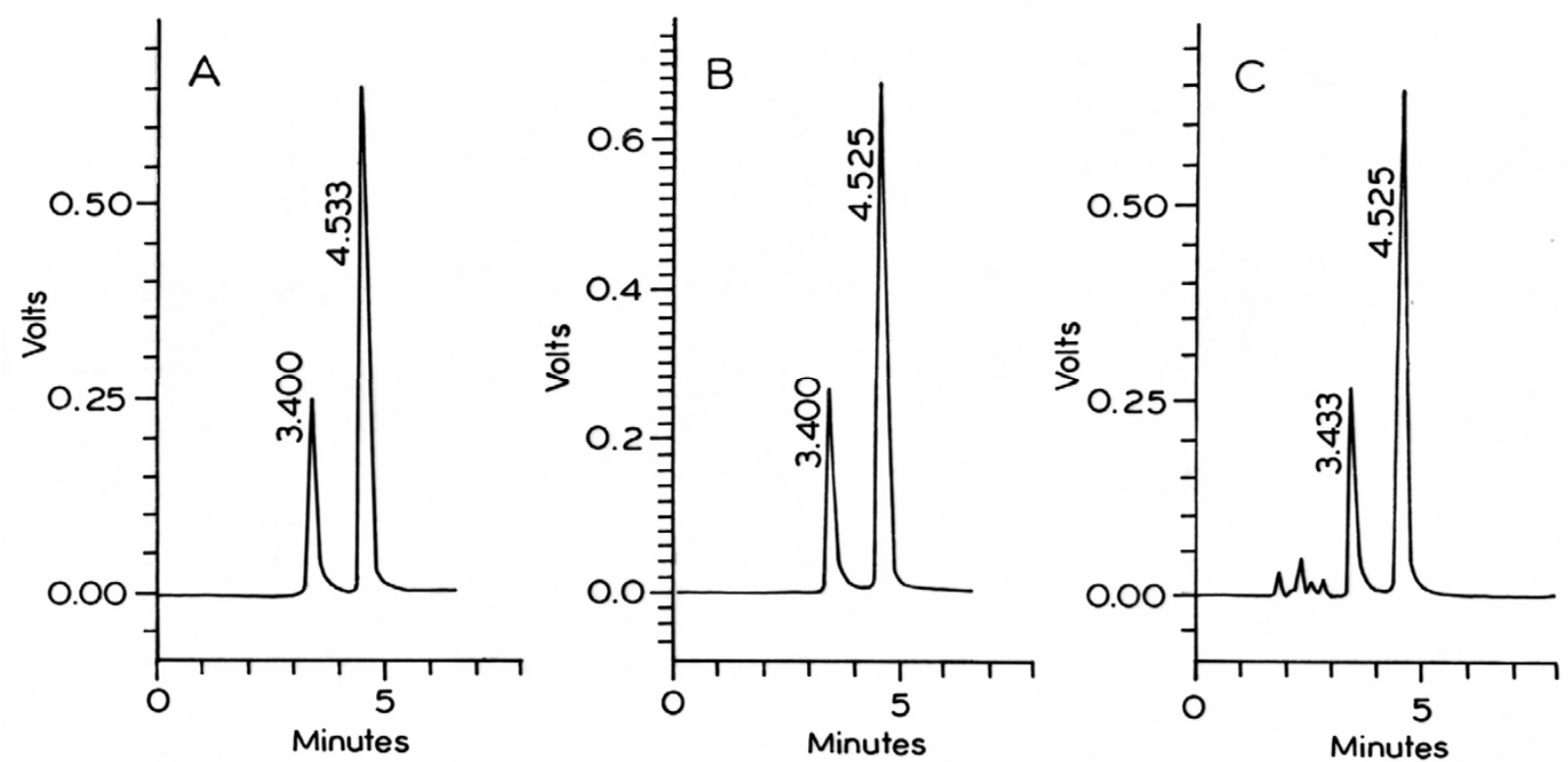

Figure I

HPLC analysis of nitrite and nitrate. Chromatograms of an aqueous standard containing $25 \mu \mathrm{M}$ nitrite and nitrate $(\mathrm{A})$ and washed and spiked Anopheles culicifacies midguts obtained under control conditions (B) and Anopheles culicifacies haemolymph. 
present in the medium. All samples from mosquitoes were spiked with $1.0,2.5,5.0,10,25,50$ and $100 \mu$ mole/ $\mathrm{l}$ of each nitrite and nitrate. Ten aliquots of each samples were chromatographed as described in section Chromatography and the resulting peak areas were compared with the peak areas that resulting from the aqueous solutions at the same concentrations (Table 1). The recovery amounts from mosquito midguts were $94.4 \pm 4.4$, $98.2+6.6,95.2 \pm 2.9,98.5 \pm 3.1$, and $99.8 \pm 1.9$ by coefficients of variations (C.V.) $5.9 \%, 5.4 \%, 6.0 \%, 4.8 \%$ and $5.1 \%$ for determination of nitrite and nitrate ( $\mu$ mole/l), respectively.

\section{Intra-day reproducibility}

Aliquots of midguts containing 1.0, 2.5, 5.0, 10 25, 50, and $100 \mu \mathrm{mole} / \mathrm{l}$ of nitrite were randomly distributed in different series of assays on the same day (Table 2). The intra-day reproducibility characterized by C.V. was $8.8 \%$, $7.1 \%, 6.7 \%, 5.1 \%$ and $4.5 \%$ for the assays of $1.0,2.5,5.0$, 10 and $25 \mu$ mole/l of nitrite respectively. Similarly, midguts containing 1.0, 2.5, 5.0, 10 and $25 \mu$ mole/l of nitrate were randomly distributed in different series of assays on the same day. The intra-day reproducibility characterized by C.V. was $8.7 \%, 7.2 \%, 3.9 \%, 3.1 \%$ and $2.2 \%$ for the assays of 1.0, 2.5, 5.0, 10 and $25 \mu \mathrm{mole} / \mathrm{l}$ of nitrate, respectively.

\section{Inter-day reproducibility}

Aliquots of midguts containing 1.0, 2.5, 5.0, 10, 25, 50, and $100 \mu \mathrm{mole} / \mathrm{l}$ of nitrite respectively were randomly distributed in different series of assays one by one during 10 days using each time the calibration curve of that day (Table 2). The inter-day reproducibility precision values characterized by C.V. was $8.8 \%, 7.1 \%, 6.7 \%, 5.1 \%$ and $4.5 \%$ for the assays of 1.0, 2.5, 5.0, 10 and $25 \mu$ mole/l of nitrite, respectively. Similarly, midguts containing 1.0, $2.5,5.0,10$ and $25 \mu \mathrm{mole} / \mathrm{l}$ of nitrate were randomly distributed in different series of assays one by one during 10 days using each time the calibration curve of that day. The inter-day reproducibility precision values characterized by C.V. were $9.9 \%, 8.5 \%, 7.2 \%, 2.9 \%$ and $3.0 \%$ for the assays of $1.0,2.5,5.0,10$ and $25 \mu$ mole/l of nitrate, respectively.

\section{Analytical findings}

Nitric oxide is produced in large quantities during the host defense and immunologic reactions having anti-inflammatory and pro inflammatory properties. Haemolymph and midgut nitrite/nitrate concentrations (Figures 2 and 3 ) in mosquitoes were found to be significantly higher then the control group (day 0 ) at any time of study ( $\mathrm{p}$ 0.029 ). There was a significant difference both in An.culicifaces species A and Species B nitrite/nitrate levels (Figure 2) at Day 7, Day 9-10, and Days 14-15 (p<0.04). The higher levels of nitrite/nitrate in midguts of refractory species $\mathrm{B}$ following $P$. vivax infected blood feeding provide new insights into the regulation of $\mathrm{NO}$ production in refractory species (Figure 3 ) and may be important for the vectorial capacity of the mosquito to elucidate the mechanism of refractoriness.

\section{Discussion}

Understanding the molecular mechanisms of the innate immune responses of Anopheles against Plasmodium parasites is of great importance for current efforts to develop novel strategies for malaria disease control [3234]. The parasite undergoes substantial stage-specific losses during its development in the mosquito, which in some cases lead to complete refractoriness of the mosquito against the parasite. The underlying genetics of refractoriness are complex and multi-factorial $[4,5]$. A variety of factors were shown to negatively affect the development of Plasmodium parasites in the mosquito, in some cases leading to complete transmission blockage [8,32-37]. Malaria parasite infection in anopheline mosquitoes is limited by inflammatory levels of nitric oxide metabolites $[13,14,38-41]$. As NO is very toxic and highly diffusible, its induction could have deleterious effects on the parasites and ookinetes invading the midgut epithe-

Table 2: Relative standard deviations (RSDs) and recoveries for $\mathrm{NO}_{2}{ }^{-}$and $\mathrm{NO}_{3}{ }^{-}$from mosquito midgut spiked with $\mathrm{I}-100 \mu \mathrm{M} \mathrm{KNO}_{2} /$ $\mathrm{KNO}_{3}($ mean $\pm \mathrm{SD}, \mathrm{n}=6$ )

\begin{tabular}{|c|c|c|c|c|c|c|}
\hline \multirow[t]{2}{*}{ Concentration $(\mu \mathrm{M})$} & \multicolumn{3}{|c|}{$\mathrm{NO}_{2}^{-}$} & \multicolumn{3}{|c|}{$\mathrm{NO}_{3}^{-}$} \\
\hline & Intra-Assay RSD (\%) & Inter-Assay RSD (\%) & Recovery (\%) & Intra-Assay RSD (\%) & Inter-Assay RSD (\%) & Recovery (\%) \\
\hline $0^{*}$ & 8.3 & 8.9 & - & 4.2 & 5.6 & - \\
\hline 1 & 8.8 & 9.3 & $94.4 \pm 4.4$ & 8.7 & 9.9 & $98.9 \pm 2.2$ \\
\hline 2.5 & 7.1 & 9.8 & $98.2+6.6$ & 7.2 & 8.5 & $98.5 \pm 2.4$ \\
\hline 5 & 6.7 & 9.9 & $95.2 \pm 2.9$ & 3.9 & 5.9 & $97.1 \pm 1.8$ \\
\hline 10 & 5.1 & 9.2 & $98.5 \pm 3.1$ & 3.1 & 2.9 & $99 \pm 5.4$ \\
\hline 25 & 4.5 & 5.3 & $99.8 \pm 1.9$ & 2.2 & 3.0 & $100 \pm 5.8$ \\
\hline 50 & 5.5 & 4.9 & $100.5 \pm 3.2$ & 2.9 & 2.6 & $94.5 \pm 6.2$ \\
\hline 100 & 3.9 & 4.7 & $97.3 \pm 2.9$ & 1.2 & 4.1 & $94.7 \pm 5.9$ \\
\hline
\end{tabular}

\footnotetext{
* Unspiked midgut samples, i.e. midgut samples to which exogenous $\mathrm{NO}_{2}{ }^{-}$and $\mathrm{NO}_{3}{ }^{-}$has not been added
} 

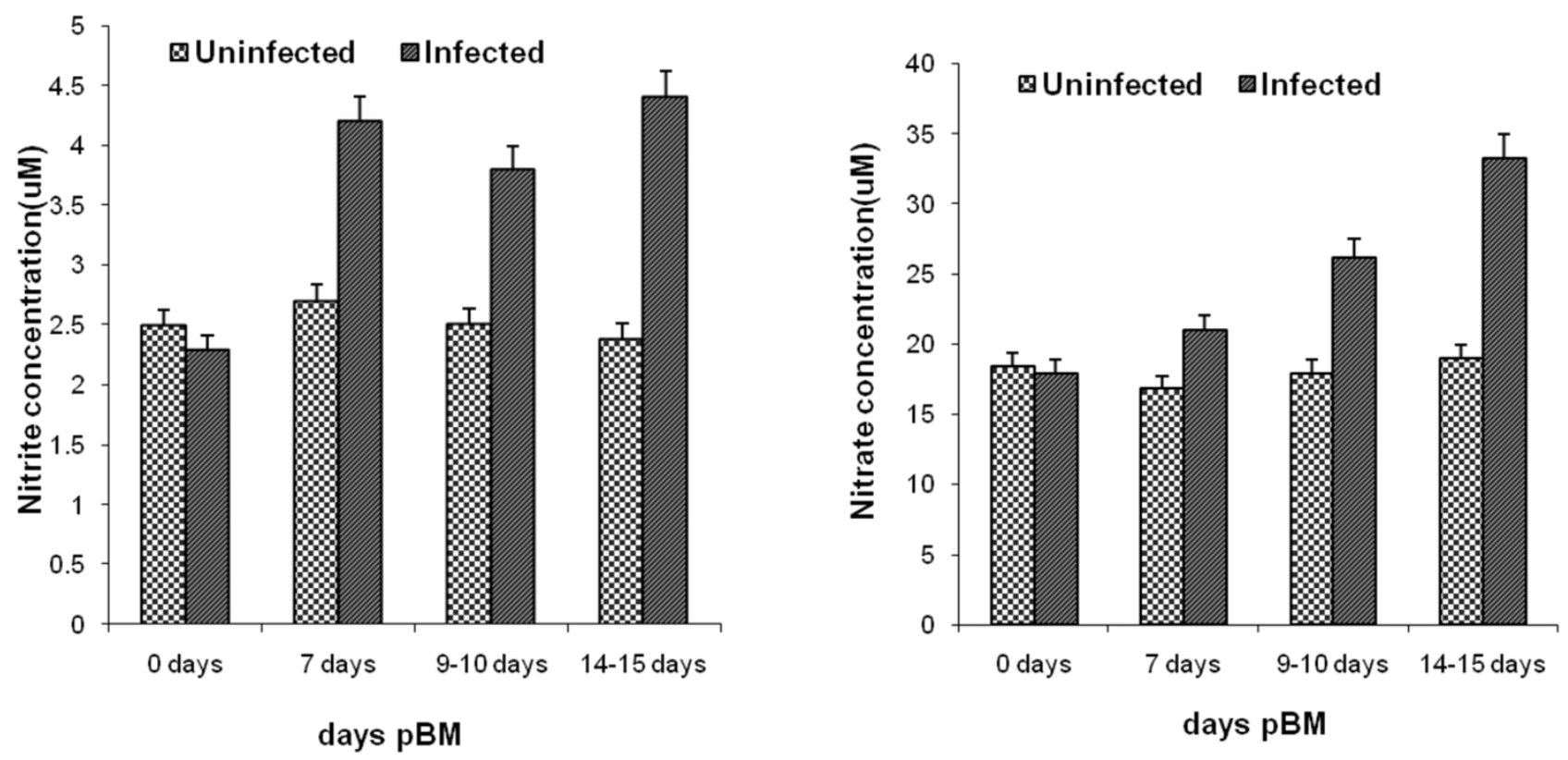

\section{Figure 2}

Haemolymph nitrite/nitrate of blood fed uninfected and blood fed Plasmodium vivax-infected Anopheles culicifacies species $B$ at $0,7,9-10$ and $I$ 4- 15 days pBM using a high performance anion liquid chromatography method. Means were analysed using a 2-way ANOVA $(p<0.05)$.

lium [42]. To assess the mechanisms of parasite stasis or toxicity, the biochemistry of these metabolites was evaluated within the blood-filled mosquito midgut as well as in the haemolymph.

Various analytical techniques have been developed to determine nitrite and nitrate, oxidation metabolites of nitric oxide (NO) in biological samples [20,25,27,43]. In previous studies nitrite/nitrate was measured after exposing plasma to copper-cadmium-Zinc catalyst to convert nitrate to nitrite and then adding the effluent of the catalyst product to griess reagent [25]. This procedure carries major disadvantages. Nitrite only is detected by griess reagent while nitrate has to be measured indirectly after reduction to nitrite. It is, therefore, not possible to predict how much of the sample's nitrate is converted to nitrite during the reductive process. Additionally, the complex formation of nitrite and griess reagent is a variable process and may influence the measurement of concentrations $[25,44]$. Griess reagent reacts with free biogenic amines other then nitrite and may produce false positive results [25]. UV/Vis absorbance [21] and electrochemistry allows simultaneous detection of nitrite and nitrate but is vulnerable to severe interference from chloride present in biological samples [20].
Chemiluminesence [23] and fluorescence detection [22] improve the assay sensitivity and is unaffected by chloride but cannot be applied to simultaneous analysis of nitrite and nitrate. Recently developed fluorometric HPLC method involves the precolumn derivatization of nitrite with 2, 3-diaminonapthalene and enzymatic conversion of nitrite to nitrate [26]. Measurement of nitric oxide itself is complicated by its short half life and would, therefore, require on-line measurement which is suitable for routine use for analysis of biological samples [45].

After an exhaustive investigation, it appears that HPLC, which is a very sensitive, rapid and accurate method with a detection limit for nitrate of $0.1 \mu \mathrm{M} / \mathrm{L}$, carries none of these disadvantages and the degradation product of nitric oxide, nitrite and nitrate are measured directly. The chromatographic system developed in this study, after investigating alternatives, readily resolved $\mathrm{NO}_{2}{ }^{-}$and $\mathrm{NO}_{3}{ }^{-}$, with peaks being separated by more then a minute as observed by Everett et al [45] Anion exchange HPLC coupled with Microsep $3 \mathrm{~K}$ filters was found to be suitable and has been advocated by other laboratories as well. Ultrafiltration devices are efficient and permit rapid and easy clean up of the samples whilst avoiding problems relating to contaminants and interfering compounds. However, a Sphereclone column, a phosphate-based eluent and an acidic $\mathrm{pH}$ were used to achieve good separation. Particular attention 

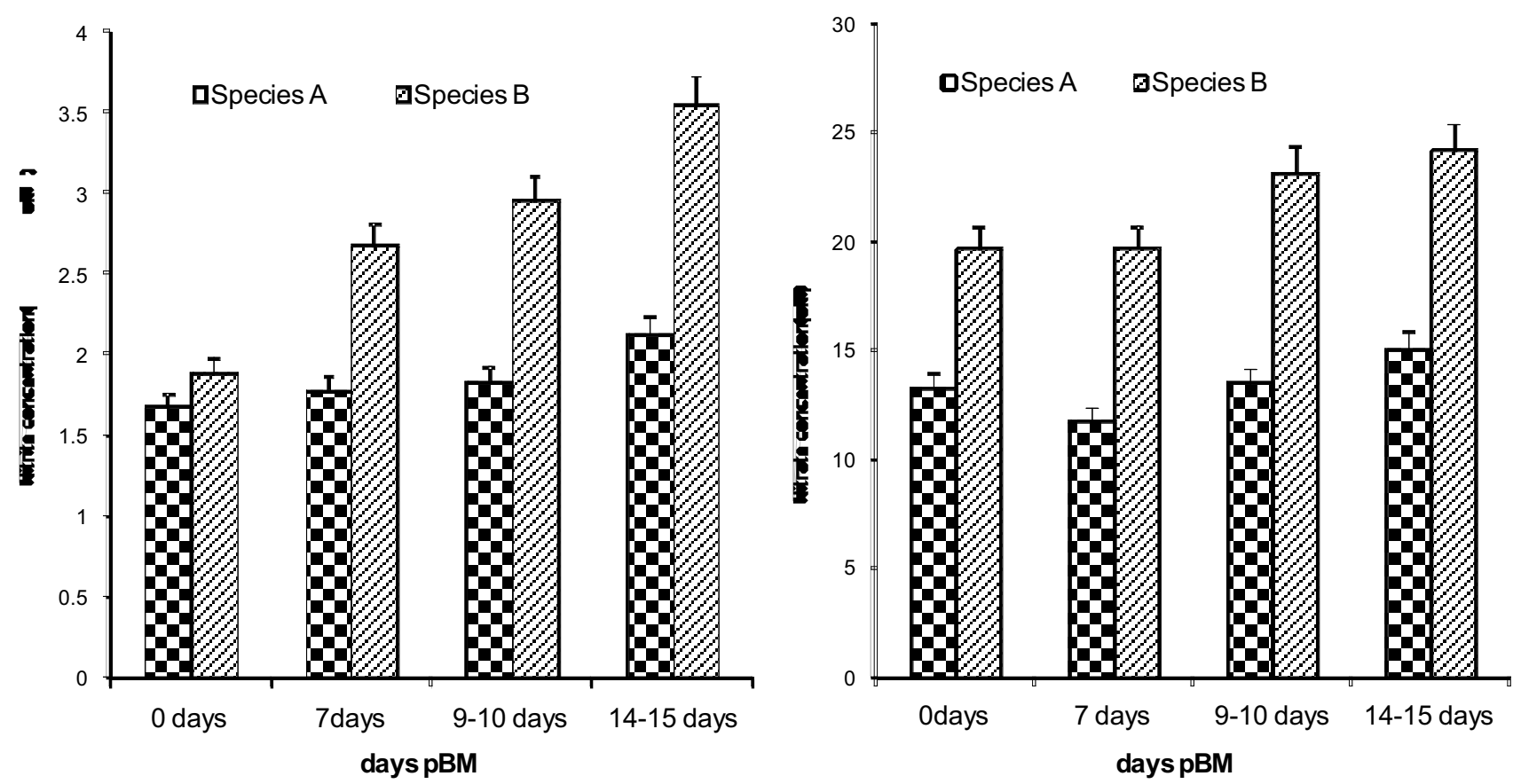

Figure 3

Midgut nitrite/nitrate of blood fed Anopheles culicifacies species A and species B at 0, 7, 9-I 0 and I4-I 5 days pBM using a high performance anion liquid chromatography method. Means were analysed using a 2-way ANOVA ( $P$ $<0.05)$.

was, however, focused on water quality and washing of plastics and glassware used for the preparation of solutions.

A procedure was developed which may have application in routine extraction and determination of $\mathrm{NO}_{2}{ }^{-}$and $\mathrm{NO}_{3}{ }^{-}$ in biological and clinical samples and offer opportunities for acquisition of data which reflects cellular generation of nitric oxide. The data indicate that circulating levels of nitrite/nitrate, end-products of NO synthesis, were significantly higher in Plasmodium-infected mosquito's midgut. This study implies that the expression of inhibitory mosquito midgut nitric oxide gene elements in response to blood meal may alter the mosquito's vectorial capacity. Mosquito molecules (NO) may be involved in oocyst killing that are refractory to the parasite and may act as an innate immune signal. This may lead to developing novel strategies for controlling the spread of malaria. Detailed knowledge of vector-parasite interactions, particularly in the midgut and the identification of critical mosquito molecules offers prospects for manipulating the vector for the control of malaria.

To date the molecular basis of refractoriness and more generally parasite recognition and killing are not well understood. The identification and cloning of genes con- ferring mosquito refractoriness to the malaria parasite is critical for understanding malaria transmission mechanisms and holds great promise for developing novel approaches to malaria control. The increase in the production of nitrite/nitrate revealed that NOS may be used as an additional effector gene to block the development of the malaria parasite in mosquitoes $[13,14,32]$. The present study furthers our understanding of the biochemistry of midgut defense reactions to parasite invasion and how these may influence the efficiency of malaria transmission by anopheline mosquitoes. The present study is highly relevant in view of the current research interest in driving the refractory genes expression into vector populations as a means of interrupting malaria transmission [42] and will provide important insight towards the development of malaria control strategies.

\section{Conclusion}

The procedure described in this paper is suitable for the routine determination of nitrite and nitrate. It has proved a sensitive, accurate and reproducible method. The principal strength of this procedure, is its simplicity. This anion HPLC method coupled with ultrafiltration to reduce protein and salt contaminants has not been used before to measure midgut and haemolymph, nitrite and nitrate concentrations in mosquitoes. This method can be used 
for the detection, identification and quantitative measurement of all nitric oxide metabolites namely nitrite and nitrate thus making it an effective tool for diagnostic purposes and useful for identifying the AcNOS gene products that may impart refractory phenotype that is associated with the immune response to malaria parasites. Such responses may be important for the vectorial capacity of the mosquito and understanding of parasite-vector interactions and mechanism of refractoriness. This procedure may also be suitable for routine determination of $\mathrm{NO}_{2}$ and $\mathrm{NO}_{3}{ }^{-}$in various other biological fluids/samples.

\section{Authors' contributions}

AS conceived and supervised the experimental work, carried out mosquito manipulation, HPLC analyses and the writing of the manuscript. KR carried out the mosquito rearing and mosquito dissections. TA carried out the mosquito membrane feeding experiments. APD provided facilities and scientific environment for experimental work. All authors read and approved the final manuscript.

\section{Acknowledgements}

The authors are thankful to Indian Council of Medical Research, New Delhi for the financial support to this work. We thank Bhanu Arya and Mrs.

Poonam Gupta for technical assistance and secretarial support.

\section{References}

I. Oaks SC, Mitchell VS, Pearson GW, Carpenter CCJ, Eds: Malaria obstacles and opportunities National Academy Press Washington USA; I991.

2. Alonso PL, Lindsay SW, Armstrong JRM, de Francisco A, Shenton FC, Greenwood BM, Conteh M, Cham K, Hill AG, David PH, Fegan G, Hall AJ: The effect of insecticide treated bed nets on mortality of Gambian children. Lancet 1991, 337:|499-502.

3. Collins FH, Besanky NJ: Vector Biology and Control of Malaria in Africa. Science 1994, 264:1874-1875.

4. Beernsten BT, James AA, Christensen BM: Genetics of mosquito vector competence. Microbiol Mol Biol Rev 2000, 64: I I5-I37.

5. Collins FH, Sakai RK, Vernick KD, Paskewitz S, Seeley DG, Miller LH, Collins WE, Campbell CC, Gwadz RW: Genetic selection of a Plasmodium-refractory strain of the malaria vector Anopheles gambiae. Science 1986, 234:607-610.

6. Feldmann AM, Ponnudurai T: Selection of Anopheles stephensi for refractoriness and susceptibility to Plasmodium falciparum. Med Vet Entomol 1989, 3:41-52.

7. Adak T, Singh OP, Nanda N, Sharma VP, Subbarao SK: Isolation of a Plasmodium vivax refractory Anopheles culicifacies strain from India. Trop Med Int Health 2006, 2:1-7.

8. Vernick KD, Fujioka H, Seeley DC, Tandler B, Aikawa M, Miller LH: Plasmodium gallinaceum: a refractory mechanism of ookinete killing in the mosquito, Anopheles gambiae. Exp Parasitol 1995, 80:583-595.

9. Abraham EG, Islam S, Srinivasan P, Ghosh AK, Valenzuela J, Ribeiro JM, Kafatos FC, Dimopoulos G, Jacobs-Lorena M: Analysis of the Plasmodium and Anopheles transcriptional repertoire during ookinete development and midgut invasion. J Biol Chem 2003, 279:5573-5580.

10. Srinivasan P, Abraham EG, Ghosh AK, Valenzuela J, Ribeiro JM, Dimopoulos G, Kafatos FC, Adams JH, Fujioka H, Jacobs-Lorena M: Analysis of the Plasmodium and Anopheles transcriptomes during oocyst differentiation. I Biol Chem 2004, 279:558I-5587.

II. Curtis CF, Pates HV, Takken W, Maxwell CA, Myamba J, Priestman A, Akinpelu O, Yayo AM, Hu JT: Biological problems with the replacement of a vector population by Plasmodium-refractory mosquitoes. Parassitologia 1999, 41:479-81.

12. Lackie AM: Immune mechanisms in insects. Parasitol Today 1988 , 4:98-105.
13. Luckart S, Vodovotz Y, Cui L, Rosenberg R: The mosquito Anopheles stephensi limits malaria parasite development with inducible synthesis of nitric oxide. Proc Natl Acad Sci USA 1998, 95:5700-5705.

14. Luckart S, Rosenberg R: Gene structure and polymorphism of an invertebrate nitric oxide synthase gene. Gene 1999, 232:25-34.

15. Lim J, Gowda DC, Krishnegowda G, Luckart S: Induction of nitric oxide synthase in Anopheles stephensi by Plasmodium falciparum: mechanism of signaling and the role of parasite glycosylphosphatidylinositols. Infect Immun 2005, 73:2778-2789.

16. Rockett KA, Awburn MM, Cowden WB, Clark IA: Killing of Plasmodium falciparum in vitro by nitric oxide derivatives. Infect Immun 1991, 59:3280-3283.

17. Giustarini D, Dalle-Donne I, Colombo R, Milzani A, Rossi R: Adaptation of the Griess reaction for detection of nitrite in human plasma. Free Radic Res 2004, 38: I235-I 240.

18. Pinto PCAG, Lima JLFC, de Sousa Saraiva MLMF: Sequential injection analysis of nitrites and nitrates in human serum using nitrate reductase. Clin Chim Acta 2003, 337:69-76.

19. Kelm M, Schrader J: Control of coronary vascular tone by nitric oxide. Circ Res 1990, 66:1561-1575

20. Tsikas D: Methods of quantitative analysis of the nitric oxide metabolites nitrite and nitrate in human biological fluids. Free Redic Res 2005, 39:797-8I5.

21. Menyawi IE, Looareesuwan S, Knapp S, Thalhammer F, Stoier B, Burgmann $\mathrm{H}$ : Measurement of serum nitrite/nitrate concentrations using high-performance liquid chromatography. J Chromatography B 1998, 706:347-35I.

22. Woitzik J, Abromeit N, Schaefer F: Measurement of nitric oxide metabolites in brain microdialysates by a sensitive fluorometric high-performance liquid chromatography assay. Anal Biochem 2001, 289:10-17.

23. Sen NP, Baddoo PA, Seaman SW: Rapid and sensitive determination of nitrite in foods and biological materials by flow injection or high-performance liquid chromatography with chemiluminescence detection. I Chromatography 1994, 673:77-84.

24. Helaleh MIH, Korenaga T: Ion chromatographic method for simultaneous determination of nitrate and nitrite in human saliva. J Chromatography 2000, 744:433-437.

25. Tsikas D, Fuchs I, Gutzki FM, Frolich JC: Measurement of nitrite and nitrate in plasma, serum and urine of humans by high performance liquid chromatography, the griess assay, chemiluminiscence and gas chromatography-mass spectrometry: Interferences by biogenic amines and $\mathbf{N}$-nitro-L arginine analogs. J Chromatography B 1998, 7 I 5:44 |-444.

26. Li H, Meininger CJ, Wu G: Rapid determination of nitrite by reversed-phase high-performance liquid chromatography with fluorescence detection. I Chromatography B 2000 , 746: 199-207.

27. Jobgen WS, Jobgen SC, Li H, Meininger CJ, Wu G: Analysis of nitrite and nitrate in biological samples using high-performance liquid chromatography. J Chromatography B 2007, 85 I:71-82.

28. Subbarao SK, Adak T, Vasantha K, Joshi H, Raghavendra K, Cochrane $\mathrm{AH}$, Nussenzweig RS, Sharma VP: Susceptibility of Anopheles culicifacies species A and B to Plasmodium vivax and Plasmodium falciparum as determined by immunoradiomatric assay. Trans R Soc Trop Med Hyg 1988, 82:394-397.

29. Medley GF, Sinden RE, Fleck S, Billingsley PF, Tirawanchi N, Rodriguez $\mathrm{MH}$ : Heterogeneity in patterns of malarial oocyst infections in the mosquito vectors. Parasitology 1993, 106:44 I-449.

30. Adak T, Kaur S, Singh OP: Comparative susceptibility of different members of the Anopheles culicifacies complex to Plasmodium vivax. Trans R Soc Trop Med Hyg 1999, 93:573-577.

31. International Conferences of Harmonization (ICH) Guidance for Bioanalytical Methods Validation Center for Evaluation and Research (CDER) 200I [http://www.fda.gov/cder/guidance/
[ 4252fnl.htm].

32. Michel K, Kafatos FC: Mosquito immunity against Plasmodium. Insect Biochem Mol Biol 2005, 35:677-689.

33. Lal AA, Schriefer ME, Sacci JB, Goldman IF, Louis-Wileman V, Collins WE, Azad AF: Inhibition of malaria parasite development in mosquitoes by anti-mosquito-midgut antibodies. Infect Immun 1994, 62:316-318. 
34. Lal AA, Patterson PS, Sacci JB, Vaughan JA, Paul C, Collins WE, Wirtz RA, Azad AF: Anti-mosquito midgut antibodies block development of Plasmodium falciparum and Plasmodium vivax in multiple species of Anopheles mosquitoes and reduce vector fecundity and survivorship. Proc Natl Acad Sci USA 200I, 98:5228-5233.

35. Peterson TM, Gow AJ, Luckhart S: Nitric oxide metabolites induced in Anopheles stephensi control malaria parasite infection. Free Radic Biol Med 2007, 42: I32-I 42.

36. Nahrevanian H, Dascombe MJ: Nitric oxide and reactive nitrogen intermediates during lethal and nonlethal strains of murine malaria. Parasitol Immunol 200I, 9:49I-50I.

37. Ito J, Ghosh A, Moreira LA, Wimmer EA, Jacobs-Lorena M: Transgenic anopheline mosquitoes impaired in transmission of a malaria parasite. Nature 2002, 4I 7:452-455.

38. Sharma A, Eapen A, Subbarao SK: Parasite killing in Plasmodium vivax malaria by nitric oxide: implication of aspartic protease inhibition. J Biochem (Tokyo) 2004, I36:329-334.

39. Wang WY, Adams DJ: Increased nitric oxide production and protection from malaria. Lancet 2003, 361:610.

40. Ascenzi P, Gradoni L: Nitric oxide limits parasite development in vectors and in invertebrate intermediate hosts. IUBMB Life 2002, 53:12I-I23.

41. Nahrevanian H, Dascombe MJ: Simultaneous increases in immune-competent cells and nitric oxide in the spleen during Plasmodium berghei infection in mice. J Microbiol Immunol Infect 2006, 39: II-17.

42. Herrera-Ortiz A, Lanz-Mendoza H, Martinez-Barnetche J, Hernandez-Martinez S, Villarreal-Trevino C, Aguilar-Marcelino L, Rodriguez $\mathrm{MH}$ : Plasmodium berghei ookinetes induce nitric oxide production in Anopheles pseudopunctipennis midguts cultured in vitro. Insect Biochem Mol Biol 2004, 34:893-90I.

43. Tsikas $D$ : Analysis of nitrite and nitrate in biological fluids by assays based on griess reaction: Appraisal of the griess reaction in the I-arginine/nitric oxide area of research. J Chromatography B 2007, 85 I:5 I-70.

44. Smith CCT, Stanyer L, Betteridge DJ: Evaluation of methods for the extraction of nitrite and nitrate in biological fluids employing high performance anion exchange liquid chromatography for their determination. J Chromatography B 2002, 779:20I-209.

45. Everett SA, Dennis MF, Tozer GM, Prise VE, Wardman P, Statford MRL: Nitric oxide in biological fluids: analysis of nitrite and nitrate by high-performance ion chromatography. J Chromatography 1995, 706:437-442.

\section{Publish with Bio Med Central and every scientist can read your work free of charge}

"BioMed Central will be the most significant development for disseminating the results of biomedical research in our lifetime. "

Sir Paul Nurse, Cancer Research UK

Your research papers will be:

- available free of charge to the entire biomedical community

- peer reviewed and published immediately upon acceptance

- cited in PubMed and archived on PubMed Central

- yours - you keep the copyright

Submit your manuscript here:

http://www.biomedcentral.com/info/publishing_adv.asp
BioMedcentral 